\title{
Brief Behavioral Response Threshold Level of a Harbor Porpoise (Phocoena phocoena) to an Impulsive Sound
}

\author{
Ronald A. Kastelein, ${ }^{1}$ Nele Steen, ${ }^{1}$ Robin Gransier, ${ }^{1}$ and Christ A. F. de Jong ${ }^{2}$ \\ ${ }^{1}$ Sea Mammal Research Company (SEAMARCO), Julianalaan 46, 3843 CC Harderwijk, The Netherlands \\ E-mail: researchteam@zonnet.nl \\ ${ }^{2}$ TNO, Acoustics and Sonar, Oude Waalsdorperweg 63, 2597 Den Haag, The Netherlands
}

\begin{abstract}
Underwater impulsive sounds may affect the behavior of harbor porpoises within a certain distance from the sound source. To determine the 50\% threshold received sound exposure level (SEL) of an impulsive sound that causes a brief behavioral response (a sudden change in swimming speed and/ or direction, similar to a startle response) in harbor porpoises, a male harbor porpoise was exposed once every $3 \mathrm{~min}$ to a single impulsive sound: a synthetic exponential pulse with a $5 \mathrm{~ms}$ time constant, reproduced by an underwater loudspeaker in a pool (resulting in a signal duration of $10 \mathrm{~ms}$ ). The sound was transmitted at seven source levels, which were expected to cause brief responses in 10 to $90 \%$ of exposures. During each transmission, the harbor porpoise's behavior was observed, and the presence or absence of a brief response was recorded. A $50 \%$ brief response rate was observed at a received SEL of $92 \mathrm{~dB}$ re $1 \mu \mathrm{Pa}^{2} \mathrm{~s}$, and a zeroto-peak sound pressure level of $122 \mathrm{~dB}$ re $1 \mu \mathrm{Pa}$. The present study suggests that a single impulsive sound as used in this study does not cause a brief response in harbor porpoises at SELs below around $65 \mathrm{~dB}$ re $1 \mu \mathrm{Pa}^{2} \mathrm{~s}$. The duration and spectrum of impulsive sounds change with distance to the sound source, and such changes may affect the responses of wild harbor porpoises.
\end{abstract}

Key Words: acoustics, anthropogenic sounds, behavior, explosion, odontocete, seismic survey

\section{Introduction}

Sound is important for marine animals as a means of orientation; communication; and to locate prey, conspecifics, and predators (Richardson et al., 1995), so marine animals are likely to be disturbed by noise in their environment. Thus, noise in the oceans caused by human activities may have negative physiological, auditory, and behavioral effects on marine fauna.
Data on the effects of noise on the harbor porpoise (Phocoena phocoena) are of particular interest because it has a wide distribution area in the northern hemisphere, the most acute hearing so far quantified in a marine mammal species, and functional hearing over a very wide frequency range (Kastelein et al., 2002, 2009, 2010). The harbor porpoise detection threshold sound exposure level (SEL) for an impulsive sound has been established (Kastelein et al., 2012b). Harbor porpoises are relatively easily deterred by anthropogenic underwater noises such as those produced by ships (Amundin \& Amundin, 1973; Polacheck \& Thorpe, 1990), acoustic alarms to prevent unwanted bycatch in gillnet fisheries (Kastelein et al., 1995, 2000, 2001; Laake et al., 1998; Culik et al., 2001; Johnston, 2002; Olesiuk et al., 2002; Teilmann et al., 2006), offshore wind turbines (Koschinski et al., 2003), underwater data communication systems (Kastelein et al., 2005b), and offshore pile driving (Carstensen et al., 2006; Tougaard et al., 2009). Avoidance threshold levels of harbor porpoises have been determined for noise bands around $12 \mathrm{kHz}$, a continuous $50 \mathrm{kHz}$ tone, and continuous and pulsed 70 and $120 \mathrm{kHz}$ tones (Kastelein et al., 2005b, 2008a, 2008b). These studies show that the spectrum, received level, and temporal patterns of underwater sounds play important roles in the effect sounds have on the behavior of harbor porpoises; behavioral responses may also depend on the bandwidth, intensity, rise time, and duration of sounds.

Brief behavioral responses (defined as sudden changes in swimming speed and/or direction) have been studied in a harbor porpoise to 1 to $2 \mathrm{kHz}$ and 6 to $7 \mathrm{kHz}$ up- and down-sweep sonar signals (described as startle responses by Kastelein et al., 2012a), and to 1.33 to $1.43 \mathrm{kHz}$ helicopter dipping sonar signals (Kastelein et al., 2013). These sounds were of durations longer than the integration time of harbor porpoise hearing (Kastelein et al., 2010). Responses to impulsive sounds may be different as was seen in bottlenose dolphins (Tursiops 
truncatus) and a beluga whale (Delphinapterus leucas; Finneran et al., 2000). Therefore, the goal of the present study was to determine the threshold, in terms of the received SEL at which an impulsive sound causes a brief response in a harbor porpoise in $50 \%$ of exposures.

\section{Methods}

\section{Study Animal}

The male harbor porpoise (identified as No. 02) used in this study was 4.5 y old. His body mass was around $38 \mathrm{~kg}$, his body length around $142 \mathrm{~cm}$, and his girth at axilla around $75 \mathrm{~cm}$. His hearing was assumed to be representative of animals his species and age because hearing data obtained from him shortly prior to the present study were similar to those from other young male harbor porpoises (Kastelein et al., 2009, 2010). The animal received between 2.3 and $3.0 \mathrm{~kg}$ of thawed fish/d, equally divided over four meals.

\section{Study Area}

The study was conducted at the SEAMARCO Research Institute, The Netherlands. Its location is remote and quiet, and was specifically selected for acoustic research. The harbor porpoise was kept alone in a pool complex which had been specifically built for acoustic research. It consisted of an outdoor pool $(12 \times 8 \mathrm{~m}, 2 \mathrm{~m}$ deep $)$ connected via a channel $(4 \times 3 \mathrm{~m}, 1.4 \mathrm{~m}$ deep) with an indoor pool $(8 \times 7$ m, 2 m deep; Figure 1). The study was conducted in the outdoor pool. The pool walls were made of plywood covered with polyester. Details of the pool are given by Kastelein et al. (2012a). The water temperature during the study varied between 1 and $5^{\circ} \mathrm{C}$; the salinity was around $34 \%$. There was no current in the pool during the experiments as the water circulation pump and air pump of the adjacent biofilter were shut off $30 \mathrm{~min}$ before and during sessions. By the time a session started, no water flowed over the skimmers so that there was little or no flow noise. The equipment used to produce the sound stimuli and record the video and audio data was housed out of sight of the study animal in a research cabin next to the pool (Figure 1).

\section{Video Equipment}

A schematic diagram of the equipment used to configure and emit outgoing sounds and to record video and underwater sounds is shown in Figure 2. The animal's behavior was filmed from above by an aerial camera (Conrad-750940, Conrad Electronic UK Ltd, Essex, UK) with a wide-angle lens. The camera was placed on a pole $9 \mathrm{~m}$ above the water surface on the northwestern side of the pool (Figure 1). The entire surface of the pool was captured on the video image. The output of the camera was fed through a video multiplexer, which added the time and date to the images.

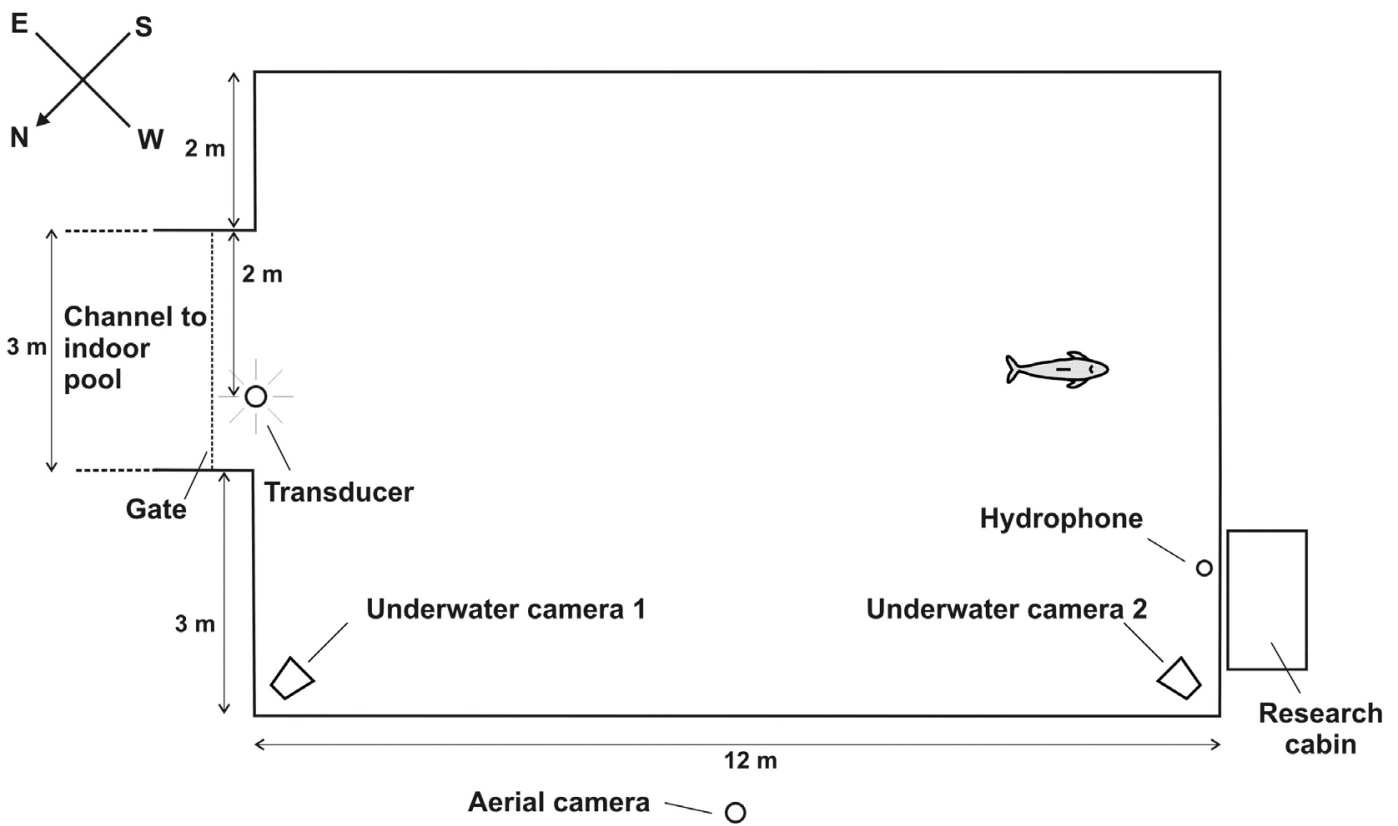

Figure 1. Top-scale view of the study facility, showing the study animal, the location of the aerial camera, the two underwater cameras, the underwater transducer emitting the impulsive sound, and the listening hydrophone; also shown is the research cabin that housed the equipment and the operator. 
Thereafter, the output was digitized by an analogto-digital converter (EZ Grabber-Vista version), stored on a laptop computer and an external hard disc (Figure 2), and made visible to the operator on the laptop screen. The harbor porpoise was also filmed by two black and white underwater cameras (Ocean Systems, Burtonsville, MD, USA) in the corners of the pool (Figure 1); the images were made visible to the operator on two TV monitors.

\section{Audio Equipment}

The digital stimulus (a WAV file of an impulsive signal; sample frequency $48 \mathrm{kHz}$ ) was played by a computer (Medion MD96780); and the output went via a custom-built digitally controlled attenuator ( 0 to $200 \mathrm{kHz}$ ) to an audio power amplifier (HQ VPA2200MBN, Velleman, Fort Worth, TX, USA; Figure 2). The sounds were projected via a balanced tonpilz piezoelectric underwater acoustic transducer (LL916, Lubell Labs, Columbus, OH, USA) suspended $1 \mathrm{~m}$ below the water surface on the northeastern side of the pool near the channel (Figure 1). The output of the sound system to the transducer was monitored with a digital storage oscilloscope (2201, Tektronix, Beaverton, OR, USA), a voltmeter (34401A, Agilent, Berkshire, UK), and a spectrum analyzer (PCSU1000, Velleman).
The audio part of the background noise and the played back sounds were recorded via a hydrophone (Model 90.02.01, LabForce, Delft, The Netherlands) and a custom-built pre-amplifier. The output of the pre-amplifier was digitized via the analog-to-digital converter and recorded on the computer. The same output was fed to an amplified loudspeaker so that the operator in the research cabin could monitor the background noise and the played back sounds during sessions. The output also went to the spectrum analyzer.

\section{Stimulus}

A single impulsive waveform with a time constant of $5 \mathrm{~ms}$, played back at various levels, was used for this study (Figures $3 \& 4$ ). Changes in spectrum over distance due to reverberation and absorption were not taken into account. Reverberation in the pool and transducer characteristics resulted in a measured mean signal duration ( $t 90$, see below) of $10(\mathrm{SD} \pm 3) \mathrm{ms}$.

\section{Acoustic Measurements}

The sound distribution of the impulsive stimulus in the pool was measured while the animal was not in the pool. The recording and analysis equipment consisted of three Brüel \& Kjær (B\&K) 8101

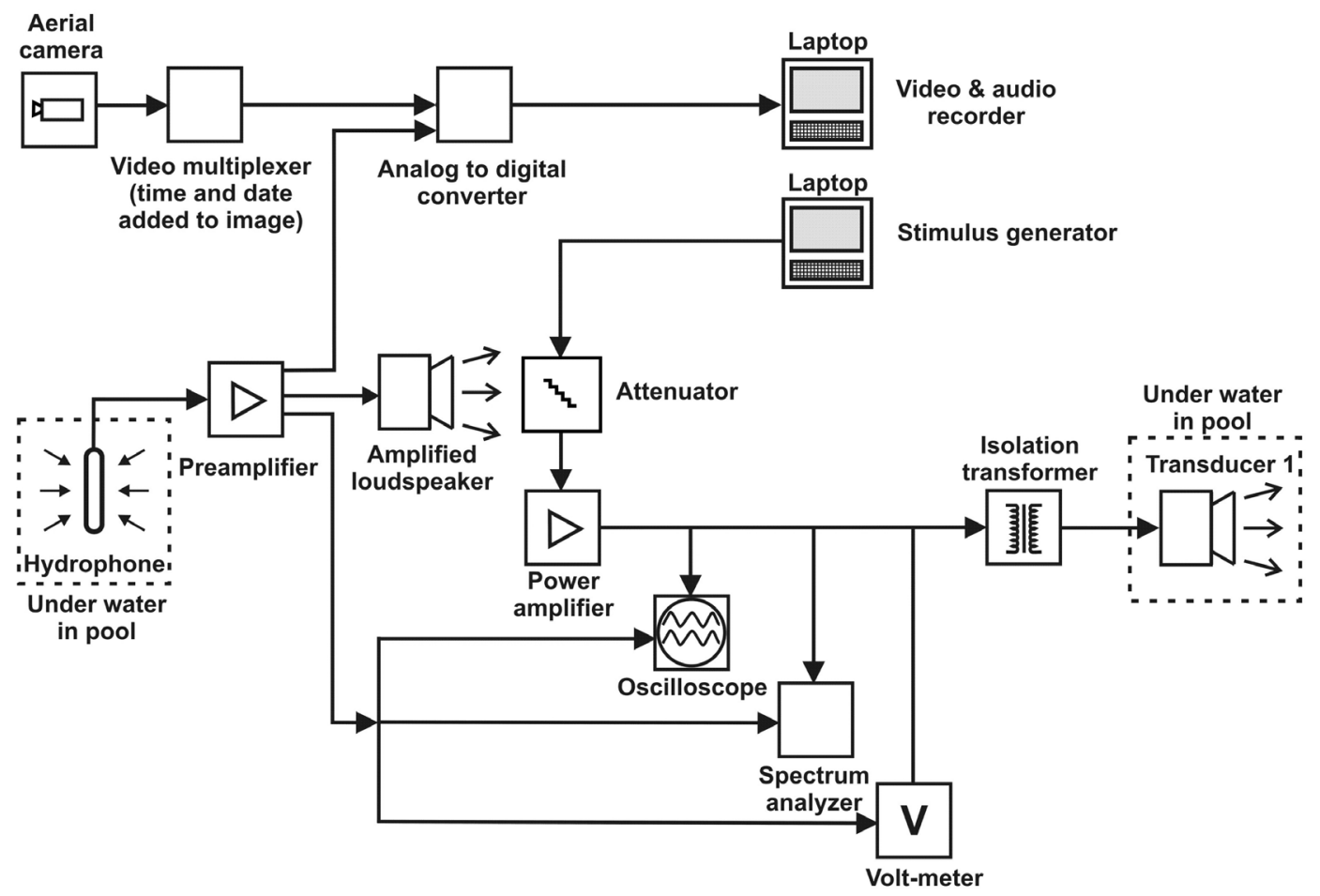

Figure 2. Block diagram of the sound generation and control systems, and the listening and recording equipment used in the harbor porpoise brief response study. 


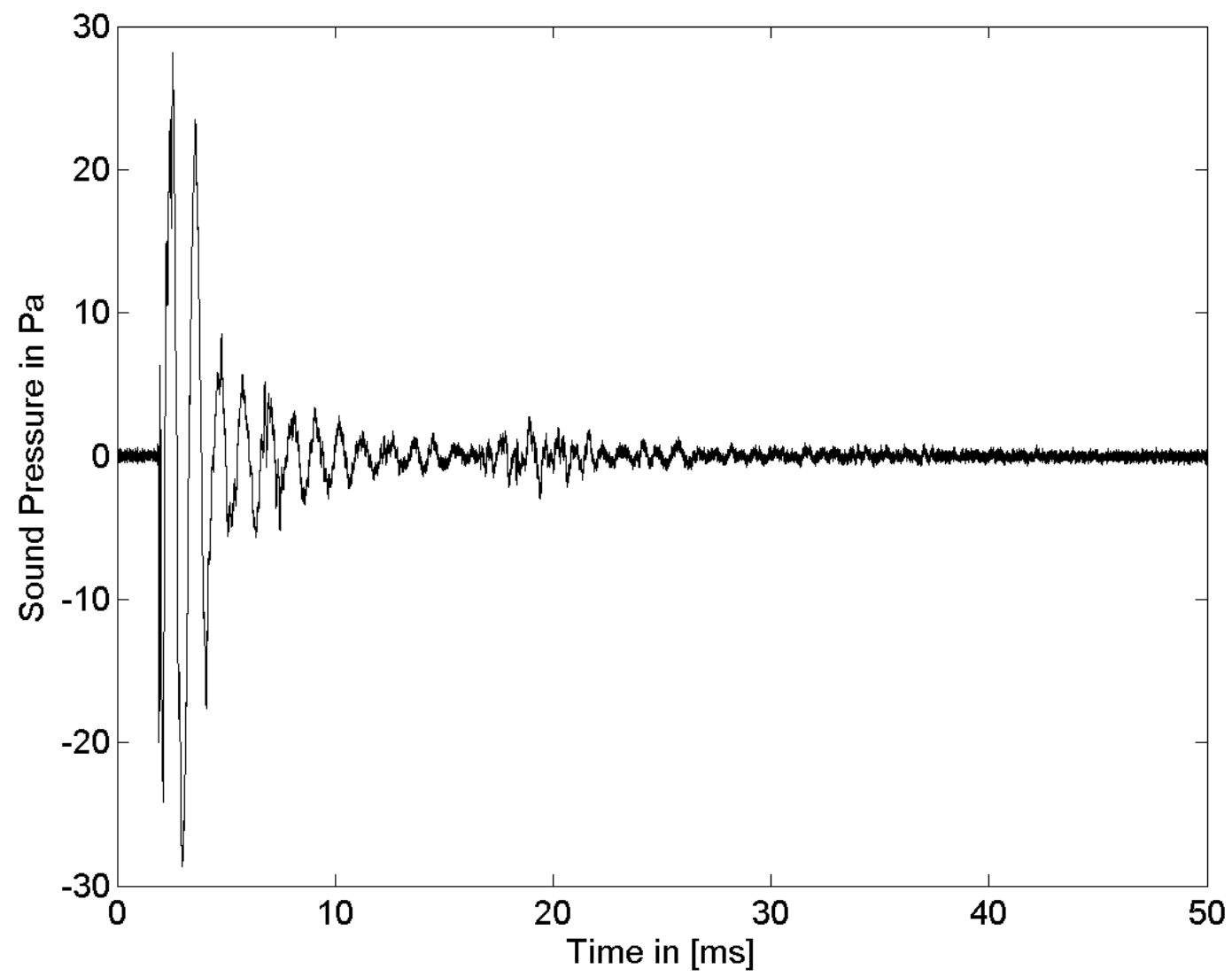

Figure 3. Waveform of the impulsive sound as recorded in the pool; the amplitude of the sound pressure is scaled to the maximum absolute value of instantaneous sound pressure.

hydrophones with custom-built power supplies, a B\&K PULSE $3560 \mathrm{D}$ multichannel high frequency analyzer, and a laptop computer with B\&K PULSE software Labshop, Version 12.1. The system was calibrated with a B\&K 4223 pistonphone.

Acoustic Characterization of the Impulsive Sounds - The impulsive sounds were characterized in terms of their unweighted SEL (in $\mathrm{dB}$ re $1 \mu \mathrm{Pa}^{2} \mathrm{~s}$ ). The duration ( $t_{90}$ in $\mathrm{s}$ ) was determined as the time interval between the points at which the cumulative sound exposure (the integrated broadband sound pressure squared) reached 5 and $95 \%$ of the total exposure- that is, the duration contained $90 \%$ of the total energy in the sound (Madsen, 2005).

Determination of the Source Levels Used in the Exposures-During a 2-wk pretest period, the playback levels of the impulsive sound were gradually increased from levels causing no behavioral response to levels which almost always caused brief responses. During the actual experiments, the played back impulsive sound was tested at seven levels (in $6 \mathrm{~dB}$ steps), which were estimated from the pretests to cause brief responses in between approximately 10 and $90 \%$ of tests.

SEL Distribution Measurements-To determine the sound distribution in the pool, the SEL of the test sound was measured at 77 locations (on a horizontal grid of $1 \mathrm{~m} \times 1 \mathrm{~m}$ ) at the playback level which resulted in brief responses in approximately $50 \%$ of exposures. The SEL was measured at three depths per location on the grid $(0.5,1.0$, and $1.5 \mathrm{~m}$ below the water surface). Thus, 231 SEL measurements were made. The sound field showed a gradient: the further away from the transducer, the lower the SEL (Figure 5). The mean (10 times the 10-base logarithm of the arithmetic mean of the 231 measurements in the pool) SEL was 90 $(\mathrm{SD} \pm 3) \mathrm{dB}$ re $1 \mu \mathrm{Pa}^{2} \mathrm{~s}$ (i.e., the middle mean SEL of the 7 mean SELs used in the study). The received SELs in the pool changed linearly in proportion to the $6 \mathrm{~dB}$ steps in the playback level.

The corresponding $t_{90}$ signal duration, averaged over all positions in the pool, was $10(\mathrm{SD} \pm 3) \mathrm{ms}$, 


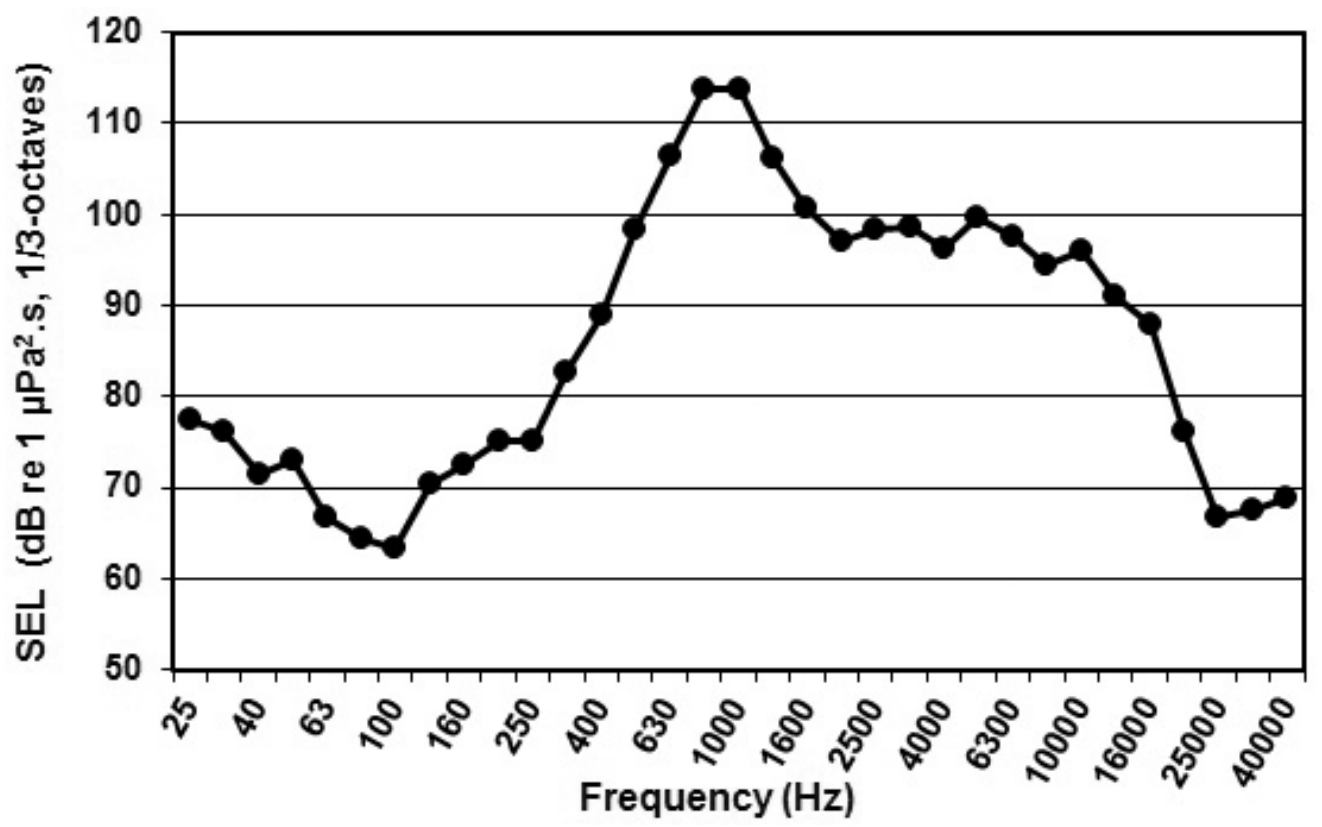

Figure 4. The 1/3-octave band spectrum of the sound exposure level (SEL) (over the $90 \%$ energy duration of the sounds) of the impulsive sound in the pool; the recording was measured $2 \mathrm{~m}$ from the transducer and had a broadband SEL of $118 \mathrm{~dB}$ re $1 \mu \mathrm{Pa}^{2} \mathrm{~s}$.

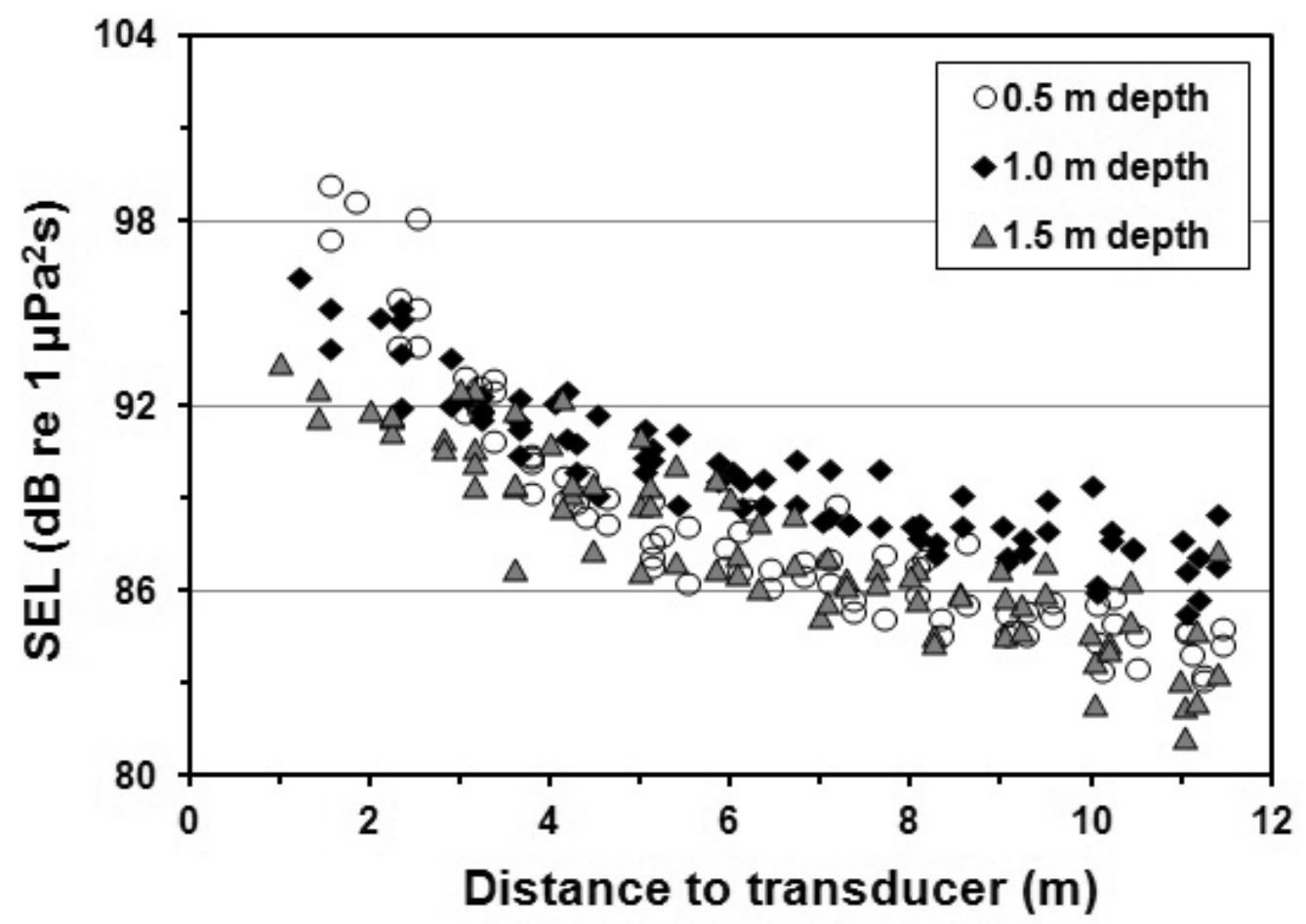

Figure 5. The SEL distribution (in $\mathrm{dB}$ re $1 \mu \mathrm{Pa}^{2} \mathrm{~s}$ ) as a function of the linear distance to the transducer (based on 231 measurements at three depths) for one of the seven source levels (mean SEL $90 \mathrm{~dB}$ re $1 \mu \mathrm{Pa}^{2} \mathrm{~s}$ ) of the impulsive sound used in the study; the sound distribution in the pool shows a gradient. The further away from the transducer the level is recorded, the lower the SEL. 
and the zero-to-peak middle sound pressure level (of the seven levels) was $120(\mathrm{SD} \pm 4$ ) $\mathrm{dB}$ re $1 \mu \mathrm{Pa}$.

\section{Experimental Procedures}

Ten minutes before each session started, the transducer producing the stimulus was positioned in the pool (Figure 1). Each session consisted of a 60 - or 90-min exposure period during which 20 or 30 impulsive sounds were emitted (one every $3 \mathrm{~min}$ ). For each emission, a source level was selected at random from all seven possible source levels. Each source level was tested 24 times during seven sessions. One session was conducted per day, normally 5 days a week, beginning between 1000 and $1100 \mathrm{~h}$. A programmable interval timer was used to tell the operator in the research cabin (via a light) when to play the stimulus WAV file. During the exposure sessions, other personnel were not allowed within $10 \mathrm{~m}$ of the pool. To ensure low ambient noise, tests were not carried out during rainfall or when the wind speed was sufficient to increase the general background noise level on the spectrum analyzer (this generally occurred above Beaufort 4). The study was conducted in February 2010.

\section{Behavioral Data Recording and Analysis}

A brief behavioral response was defined as a sudden change in swimming speed and/or swimming direction during the sound emission, or in the 1 -s period immediately after the sound emission. For consistency, all the emissions were evaluated by the same person, who was not aware of the SEL at which the impulsive sound was projected. The outcome was simple: a brief response either occurred or did not occur. In all cases, the behavior was very clear-cut and easy to categorize.

The location of the animal in the pool at the transmission time varied as the time of sound emission was determined by a programmable timer (once every $3 \mathrm{~min}$ ). The mean SEL of all 231 measurements was used to approximate the level received by the harbor porpoise for each playback setting. The percentage of emissions at each setting resulting in a brief response was plotted against the mean SEL. From this psychometric function, the 50\% brief response threshold SEL of the harbor porpoise was determined by using linear interpolation.

\section{Results}

When no sounds were emitted, the harbor porpoise usually swam large clockwise ovals in the pool and made regular long dives alternated with shorter dives. The psychometric function shows that, during sound emissions, the brief response rate increased as the mean received SEL increased (Figure 6; linear regression: \% response $=1.86 \times$ mean received SEL -120.98; $\mathrm{R}^{2}=0.98$ ). All the observed brief responses occurred during or within $1 \mathrm{~s}$ of the transmissions of the impulsive sound and consisted of approximately one strong tail movement bringing about a sudden change in swimming speed and direction after which the animal's behavior returned to normal. The animal did not avoid the area near the underwater transducer during sessions. Interpolating from the results presented in Figure 6, brief responses occurred in $50 \%$ of emissions at an average broadband single-pulse SEL of $92 \mathrm{~dB}$ re $1 \mu \mathrm{Pa}^{2} \mathrm{~s}$, and a zero-to-peak pressure level of $122 \mathrm{~dB}$ re $1 \mu \mathrm{Pa}$. The present study suggests that a single impulsive sound does not cause a brief response in harbor porpoises at SELs below around $65 \mathrm{~dB}$ re $1 \mu \mathrm{Pa}^{2} \mathrm{~s}$.

\section{Discussion}

The study was conducted with only one animal, but his hearing was very similar to that of another male harbor porpoise of the same age (Kastelein et al., 2009) and to that of another male (Kastelein et al., 2002, 2010), and so, it was likely to be representative for harbor porpoises.

After each session, the animal's behavior immediately returned to normal. He cooperated in a psycho-acoustic test only minutes after the last impulsive sound was emitted, showing that the stimulus at the levels of the present study had no long-lasting effects on the animal's behavior or hearing for broadband signals (no temporary hearing threshold shift occurred; Kastelein et al., 2012b).

The $50 \%$ brief response mean received SEL (92 dB re $1 \mu \mathrm{Pa}^{2} \mathrm{~s}$ ) found in the present study was $32 \mathrm{~dB}$ higher than the $50 \%$ detection threshold level $\left(60 \mathrm{~dB}\right.$ re $\left.1 \mu \mathrm{Pa}^{2} \mathrm{~s}\right)$ for a similar impulsive sound in the same pool (Kastelein et al., 2012b). Both studies were conducted in the same quiet environment and with sufficiently high signal to noise ratios. However, different transducers were used, and as a result, the mean $t_{90}$ of the sounds in the two studies differed (34 $\mathrm{ms}$ in the hearing study and $10 \mathrm{~ms}$ in the present study).

Due to propagation and reverberation, the level and duration of the impulsive sound varied depending on the location in the pool, but the sound emission times were regular, so the location of the animal varied at random during sound emissions. The animal had no favorite location in the pool. Therefore, any location effects and differences in received level and signal duration were randomized among all seven source levels.

The hearing of harbor porpoises is directional (Kastelein et al., 2005a) so that the orientation of the harbor porpoise influenced the perceived SEL in this study. However, to some degree, this directionality effect was counterbalanced by the 


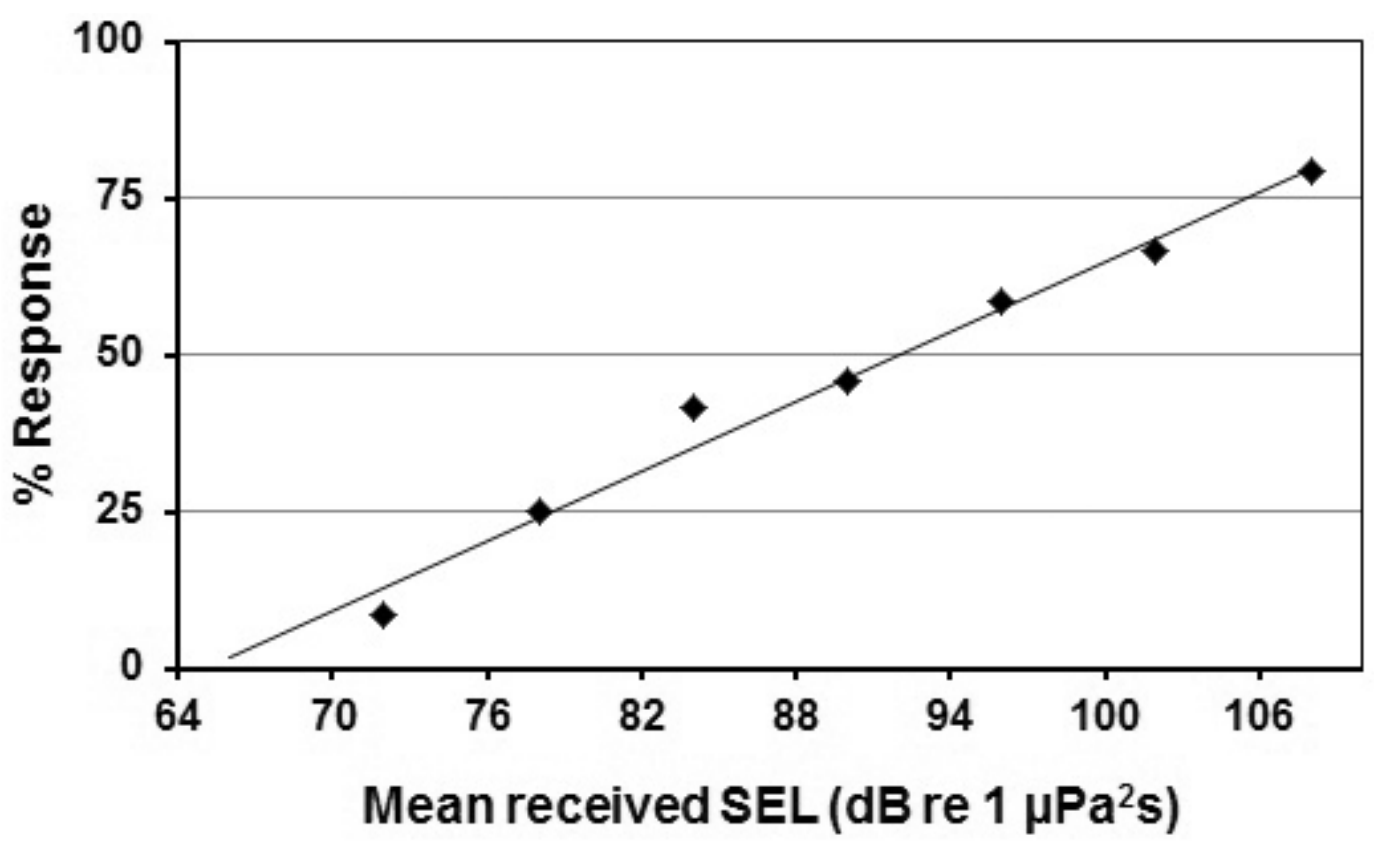

Figure 6. The mean received SEL vs the brief response rate of the male harbor porpoise for an impulsive sound; each of the seven data points is based on 24 sound emissions tested in several sessions over a 1-mo period. For the mean received peak sound pressure levels, add $30 \mathrm{~dB}$ to the SEL values. The line shows the linear regression $\left(\mathrm{y}=1.86 \mathrm{x}-120.98 ; \mathrm{R}^{2}=0.98\right)$.

reverberations in the pool. The stimulus levels were variable, but the behavioral responses were highly consistent. Evidently, 24 sound transmissions per level were enough to even out small inter-trial differences in received levels for each of the seven levels to which the harbor porpoise was exposed.

No habituation was observed in the harbor porpoise's response to the impulsive sound during the course of the study. This suggests that the brief response was a startle response.

The effects observed in the present study occurred under very low background noise conditions. Under higher background noise conditions, levels required to cause brief responses may be higher as was observed in the same harbor porpoise for 6 to $7 \mathrm{kHz}$ up-sweeps transmitted under ambient noise conditions resembling those of several different sea states (Kastelein et al., 2011).

The brief response occurs somewhere on the gradient of received SELs which influence an animal's behavior. The present study indicates (by extrapolation) that, in quiet background noise conditions, a single impulsive sound does not cause a brief response in harbor porpoises for received SELs below around $65 \mathrm{~dB}$ re $1 \mu \mathrm{Pa}^{2}$ s. The brief behavioral response is similar to a startle response, which initiates fight or flight behavior in animals that are facing external threats and is an index of the preparatory state of the animal (Fox et al., 2006). Whether or not a harbor porpoise that is startled by a sound actually flees the area depends on the level of arousal in the animal and on whether the sound is perceived as a threat, but also on other factors, such as the energetic costs and benefits of staying in or leaving the area.

The perceived durations and spectra of impulsive sounds change with distance, and this should be taken into account when calculating behavioral effect ranges for wild harbor porpoises.

\section{Acknowledgments}

We thank Lean Hoek for managing the students and the daily schedule at the SEAMARCO Research Institute to allow time for the study sessions, and for her constructive comments on this manuscript. We thank Rob Triesscheijn for making some of the figures, and Bert Meijering (Topsy Baits) for providing space for the SEAMARCO Research Institute. We thank Erwin Jansen (TNO) for the acoustic measurements, and Arie Smink for the construction and maintenance of the electronic equipment. We also thank Nancy Jennings (dotmoth.co.uk, Bristol, UK), Wim Verboom (JunoBioacoustics), and two anonymous reviewers for their valuable constructive comments on the manuscript. The harbor porpoise was made available by the SOS Dolfijn Foundation, Harderwijk, 
The Netherlands. The harbor porpoise was tested under authorization of The Netherlands Ministry of Economic Affairs, Department of Nature Management, with Endangered Species Permit FF/75A/2009/039. We thank Jan van Spaandonk (The Netherlands Ministry of Economic Affairs) for his assistance in making the harbor porpoise available for this project. Funding was obtained from The Netherlands Ministry of Defense (contract WO Geluidsduur Zeezoogdieren 235-086006-01). We thank Vincent Gales and Ronald de Rooij (The Netherlands Ministry of Defense), and René Dekeling (Royal Netherlands Navy) for making the funding possible.

\section{Literature Cited}

Amundin, M., \& Amundin, B. (1973). On the behaviour and study of the harbour porpoise (Phocoena phocoena) in the wild. In G. Pilleri (Ed.), Investigations on Cetacea (Vol. 5, pp. 317-328). Bern, Switzerland: Institute for Brain Research.

Carstensen, J., Hendriksen, O. D., \& Teilmann, J. (2006). Impacts of offshore wind farm construction on harbour porpoises: Acoustic monitoring of echolocation activity using porpoise detectors (T-POSs). Marine Ecology Progress Series, 321, 295-308. http://dx.doi. org/10.3354/meps321295

Culik, B. M., Koschinski, S., Tregenza, N., \& Ellis, G. M. (2001). Reactions of harbour porpoises Phocoena phocoena and herring Clupea harengus to acoustic alarms. Marine Ecological Progress Series, 211, 255-260. http:// dx.doi.org/10.3354/meps211255

Finneran, J. J., Schlundt, C. E., Carder, D. A., Clark, J. A., Young, J. A., Gaspin, J. B., \& Ridgway, S. H. (2000). Auditory and behavioral responses of bottlenose dolphins (Tursiops truncatus) and a beluga whale (Delphinapterus leucas) to impulsive sounds resembling distant signatures of underwater explosion. The Journal of the Acoustical Society of America, 108(1), 417-431. http://dx.doi.org/ 10.1121/1.429475

Fox, N. A., Hane, A. A., \& Pérez-Edgar, K. (2006). Psychophysiological methods for the study of developmental psychopathology. In D. Cicchetti \& D. J. Cohen (Eds.), Developmental psychopathology (Vol. 1, pp. 381426). Hoboken, NJ: John Wiley \& Sons.

Johnston, D. W. (2002). The effect of acoustic harassment devices on harbour porpoises (Phocoena phocoena) in the Bay of Fundy, Canada. Biological Conservation, 108(1), 113-118. http://dx.doi.org/10.1016/S0006-3207 (02)00099-X

Kastelein, R. A., Goodson, A. D., Lien, J., \& de Haan, D. (1995). The effects of acoustic alarms on harbour porpoise (Phocoena phocoena) behaviour. In P. E. Nachtigall, J. Lien, W. W. L. Au, \& A. J. Read (Eds.), Harbour porpoises: Laboratory studies to reduce bycatch (pp. 157167). Woerden, The Netherlands: De Spil Publishers.
Kastelein, R. A., Gransier, R., Hoek, L., \& de Jong, C. A. F. (2012b). The hearing threshold of a harbor porpoise (Phocoena phocoena) for impulsive sounds (L). The Journal of the Acoustical Society of America, 132(2), 607-610. http://dx.doi.org/10.1121/1.4733552

Kastelein, R. A., Gransier, R., van den Hoogen, M., \& Hoek, L. (2013). Brief behavioral response threshold levels of a harbor porpoise (Phocoena phocoena) to five helicopter dipping sonar signals (1.33 to $1.43 \mathrm{kHz}$ ). Aquatic Mammals, 39(2), 162-173. http://dx.doi.org/10.1578/AM.39.2.2013.162

Kastelein, R. A., Hoek, L., de Jong, C. A. F., \& Wensveen, P. J. (2010). The effect of signal duration on the underwater detection thresholds of a harbor porpoise (Phocoena phocoena) for single frequency-modulated tonal signals between 0.25 and $160 \mathrm{kHz}$. The Journal of the Acoustical Society of America, 128(5), 3211-3222. http://dx.doi.org/10.1121/1.3493435

Kastelein, R. A., Janssen, J., Verboom, W. C., \& de Haan, D. (2005a). Receiving beam patterns in the horizontal plane of a harbor porpoise (Phocoena phocoena). The Journal of the Acoustical Society of America, 118(2), 1172-1179. http://dx.doi.org/10.1121/1.1945565

Kastelein, R. A., Verboom, W. C., Jennings, N., \& de Haan, D. (2008a). Behavioral avoidance threshold level of a harbor porpoise (Phocoena phocoena) for a continuous $50 \mathrm{kHz}$ pure tone (L). The Journal of the Acoustical Society of America, 123(4), 1858-1861. http://dx.doi. org/10.1121/1.2874557

Kastelein, R. A., Bunskoek, P., Hagedoorn, M., Au, W. W. L., \& de Haan, D. (2002). Audiogram of a harbor porpoise (Phocoena phocoena) measured with narrow-band frequency-modulated signals. The Journal of the Acoustical Society of America, 112(1), 334-344. http://dx.doi.org/ $10.1121 / 1.1480835$

Kastelein, R. A., de Haan, D., Vaughan, N., Staal, C., \& Schooneman, N. M. (2001). The influence of three acoustic alarms on the behaviour of harbour porpoises (Phocoena phocoena) in a floating pen. Marine Environmental Research, 52(4), 351-371. http://dx.doi. org/10.1016/S0141-1136(01)00090-3

Kastelein, R. A., Steen, N., de Jong, C. A. F., Wensveen, P. J., \& Verboom, W. C. (2011). Effect of broadbandnoise masking on the behavioral response of a harbor porpoise (Phocoena phocoena) to 1-s duration 6-7 kHz sonar up-sweeps. The Journal of the Acoustical Society of America, 129(4), 2307-2315. http://dx.doi. org/10.1121/1.3559679

Kastelein, R. A., Steen, N., Gransier, R., Wensveen, P. J., \& de Jong, C. A. F. (2012a). Threshold received sound pressure levels of single $1-2 \mathrm{kHz}$ and $6-7 \mathrm{kHz}$ upsweeps and down-sweeps causing startle responses in a harbor porpoise (Phocoena phocoena). The Journal of the Acoustical Society of America, 131(3), 2325-2333. http://dx.doi.org/10.1121/1.3682032

Kastelein, R. A., Verboom, W. C., Jennings, N., de Haan, D., \& van der Heul, S. (2008b). The influence of 70 and $120 \mathrm{kHz}$ tonal signals on the behavior of harbor porpoises (Phocoena phocoena) in a floating pen. Marine 
Environmental Research, 66(3), 319-326. http://dx.doi. org/10.1016/j.marenvres.2008.05.005

Kastelein, R. A., Verboom, W. C., Muijsers, M., Jennings, N. V., \& van der Heul, S. (2005b). The influence of acoustic emissions for underwater data transmission on the behaviour of harbour porpoises (Phocoena phocoena) in a floating pen. Marine Environmental Research, 59(4), 287-307. http://dx.doi.org/10.1016/j. marenvres.2004.05.005

Kastelein, R. A., Rippe, H. T., Vaughan, N., Schooneman, N. M., Verboom, W. C., \& de Haan, D. (2000). The effect of acoustic alarms on the behavior of harbor porpoises (Phocoena phocoena) in a floating pen. Marine Mammal Science, 16(1), 46-64. http://dx.doi. org/10.1111/j.1748-7692.2000.tb00903.x

Kastelein, R. A., Wensveen, P. J., Hoek, L., Au, W. W. L., Terhune, J. M., \& de Jong, C. A. F. (2009). Critical ratios in harbor porpoises (Phocoena phocoena) for tonal signals between 0.315 and $150 \mathrm{kHz}$ in random Gaussian white noise. The Journal of the Acoustical Society of America, 126(3), 1588-1597. http://dx.doi. org/10.1121/1.3177274

Koschinski, S., Culik, B. M., Hendriksen, O. D., Tregenza, N., Ellis, G., Jansen, C., \& Kathe, G. (2003). Behavioural reactions of free-ranging porpoises and seals to noise of a simulated $2 \mathrm{MW}$ windpower generator. Marine Ecology Progress Series, 265, 263-273. http://dx.doi.org/10.3354/ meps 265263

Laake, J., Rugh, D., \& Baraff, L. (1998). Observations of harbor porpoise in the vicinity of acoustic alarms on a set gill net (NOAA Technical Memorandum NMFS-AFSC-84). Washington, DC: U.S. Department of Commerce. 40 pp.

Madsen, P. T. (2005). Marine mammals and noise: Problems with root mean square sound pressure levels for transients. The Journal of the Acoustical Society of America, 117(6), 3952-3957. http://dx.doi.org/10.1121/1.1921508

Olesiuk, P. F., Nichol, L. M., Sowden, M. J., \& Ford, J. K. B. (2002). Effect of sound generated by an acoustic harassment device on the relative abundance of harbor porpoises (Phocoena phocoena) in Retreat Passage, British Columbia. Marine Mammal Science, 18(4), 843-862. http://dx.doi.org/10.1111/j.1748-7692.2002.tb01077.x

Polacheck, T., \& Thorpe, L. (1990). The swimming direction of harbor porpoises in relationship to a survey vessel. Report of the International Whaling Commission, 40, 463-470.

Richardson, W. J., Greene, C. R., Jr., Malme, C. I., \& Thomson, D. H. (1995). Marine mammals and noise. San Diego: Academic Press. 576 pp.

Teilmann, J., Tougaard, J., Miller, L. A., Kirketerp, T., Hansen, K., \& Brando, S. (2006). Reactions of captive harbor porpoises (Phocoena phocoena) to pingerlike sounds. Marine Mammal Science, 22(2), 240-260. http://dx.doi.org/10.1111/j.1748-7692.2006.00031.x

Tougaard, J., Carstensen, J., Teilmann, J., Skov, H., \& Rasmussen, P. (2009). Pile driving zone of responsiveness extends beyond $20 \mathrm{~km}$ for harbor porpoises (Phocoena phocoena [L.]). The Journal of the
Acoustical Society of America, 126(1), 11-14. http:// dx.doi.org/10.1121/1.3132523 